\title{
Ascariasis and Cardiac Surgery: A Case Report
}

\author{
Ajmer Singh ${ }^{1}$ Ravi K Mahavar ${ }^{1}$ Yatin Mehta ${ }^{2}$ \\ ${ }^{1}$ Department of Cardiac Anaesthesia, Medanta-The Medicity, \\ Gurugram, Haryana, India \\ 2 Institute of Critical Care and Anesthesiology, Medanta-The \\ Medicity, Gurugram, Haryana, India
}

\author{
Address for correspondence Ajmer Singh, MD, Institute of Critical \\ Care and Anesthesiology, Medanta-The Medicity, Sector-38, \\ Gurugram, Haryana, 122001, India \\ (e-mail: ajmersingh@yahoo.com).
}

J Card Crit Care 2021;5:169-170.

\begin{abstract}
Keywords

- Ascaris

- Cardiac Surgery

- Eosinophilia

Ascariasis is a common helminthic infection, particularly in the tropical countries. We describe a case of eosinophilia who underwent coronary artery bypass graft (CABG) surgery. Postoperatively, he was found to have ascaris lumbricoides in the oral cavity. Timely detection and removal of the worm prevented the possible complications such as airway obstruction, bronchospasm, lung collapse, or intestinal obstruction. The case emphasizes the importance of considering parasitic infection as a differential diagnosis in patients presenting with eosinophilia for elective surgery.
\end{abstract}

\section{Introduction}

In the tropical countries, ascariasis is the most commonly seen helminthic infection, with an estimated prevalence of approximately $25 \% .^{1}$ Children and malnourished individuals with poor sanitation and personal hygiene are more commonly affected. Depending on its developmental stage, it can cause various complications such as airway obstruction, bronchospasm, pneumonitis, lung collapse, or intestinal obstruction in the perioperative period. ${ }^{1}$ Adult worms can migrate to some other sites, causing pancreatitis, biliary obstruction, cholangiohepatitis, liver abscess, appendicitis, intestinal perforation, granulomatous peritonitis, and ascaris empyema. $^{2}$

\section{Case Report}

We describe a 43-year-old patient admitted for coronary artery bypass graft (CABG) surgery, who was found to have eosinophilia (differential eosinophils $13.6 \%$, absolute eosinophil count 980 cells $/ \mathrm{mm}^{3}$ ) on preoperative workup. Single dose of albendazole $400 \mathrm{mg}$ was administered and the patient underwent off-pump CABG surgery. In the postoperative period, while on mechanical ventilation, the nurse noticed a large worm ( $25 \mathrm{~cm}$ long) lying in the oral cavity, which was

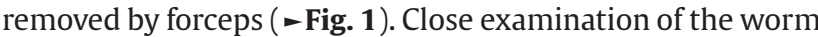
by microbiologist confirmed the diagnosis of ascaris lumbricoides ( $\mathbf{- F i g . 2}$ ). The patient received anthelmintic therapy in the form of albendazole and ivermectin. Subsequent course in the hospital was uneventful.

\section{Discussion}

Most cases of ascaris lumbricoides are asymptomatic. Humans are affected by ingestion of eggs from contaminated food, water, and infected soil. The adult worms live in the jejunal lumen and are known to migrate into the most unusual locations in the body. The clinical spectrum of the disease involves pulmonary, intestinal, pancreatic, and hepatobiliary systems. ${ }^{3}$ Peripheral eosinophilia, resulting from larval invasion of the blood, is commonly seen. Therefore, presence of eosinophilia should raise the suspicion of ascaris infestation. The diagnosis is confirmed by stool examination, and the treatment consists of deworming with oral anthelmintics.

While peristalsis helps in passage of worms via stool, reverse peristalsis can push them into the oral cavity. Other possible mechanisms of upward migration after surgery include supine posture of the patient, relaxed esophageal sphincter, presence of nasogastric tube, absent swallowing published online January 22, 2021
DOI https://doi.org/

$10.1055 / \mathrm{s}-0041-1723627$ ISSN 2457-0206. (c) 2020. Official Publication of The Simulation Society (TSS), accredited by International Society of Cardiovascular Ultrasound (ISCU).

This is an open access article published by Thieme under the terms of the Creative Commons Attribution-NonDerivative-NonCommercial-License, permitting copying and reproduction so long as the original work is given appropriate credit. Contents may not be used for commercial purposes, or adapted, remixed, transformed or built upon. (https://creativecommons.org/licenses/by-nc-nd/4.0/) Thieme Medical and Scientific Publishers Pvt. Ltd., A-12, 2nd Floor, Sector 2, Noida-201301 UP, India 


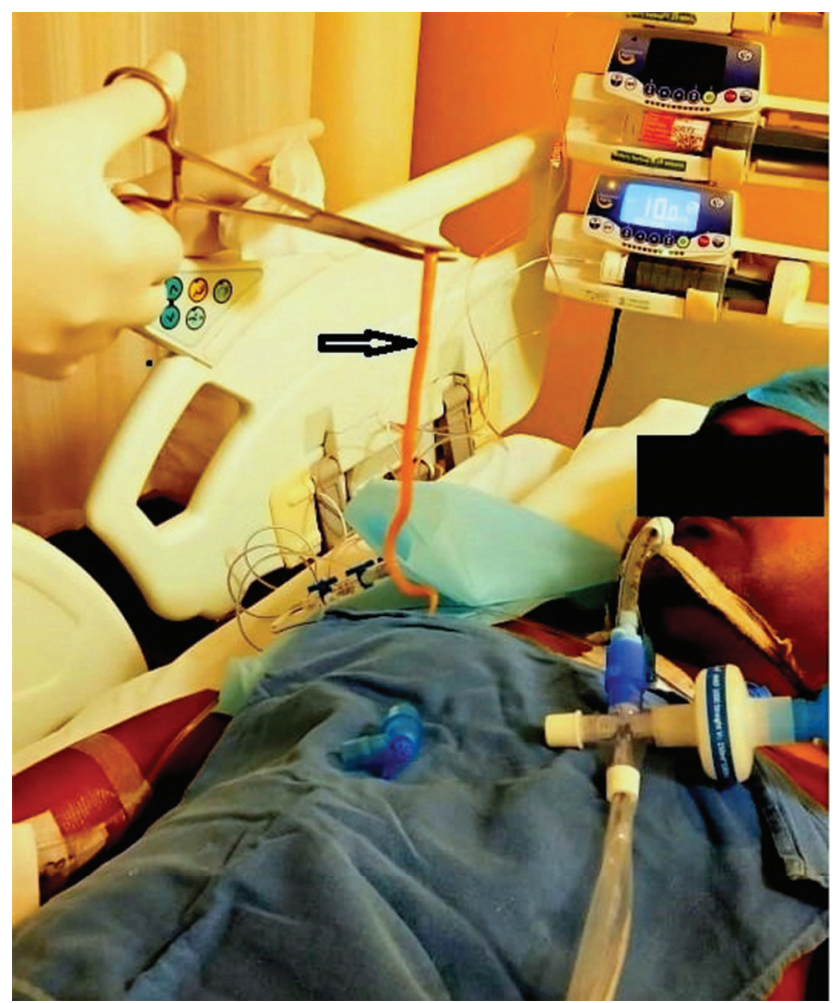

Fig. 1 An ascaris worm (arrow) removed from the oral cavity.

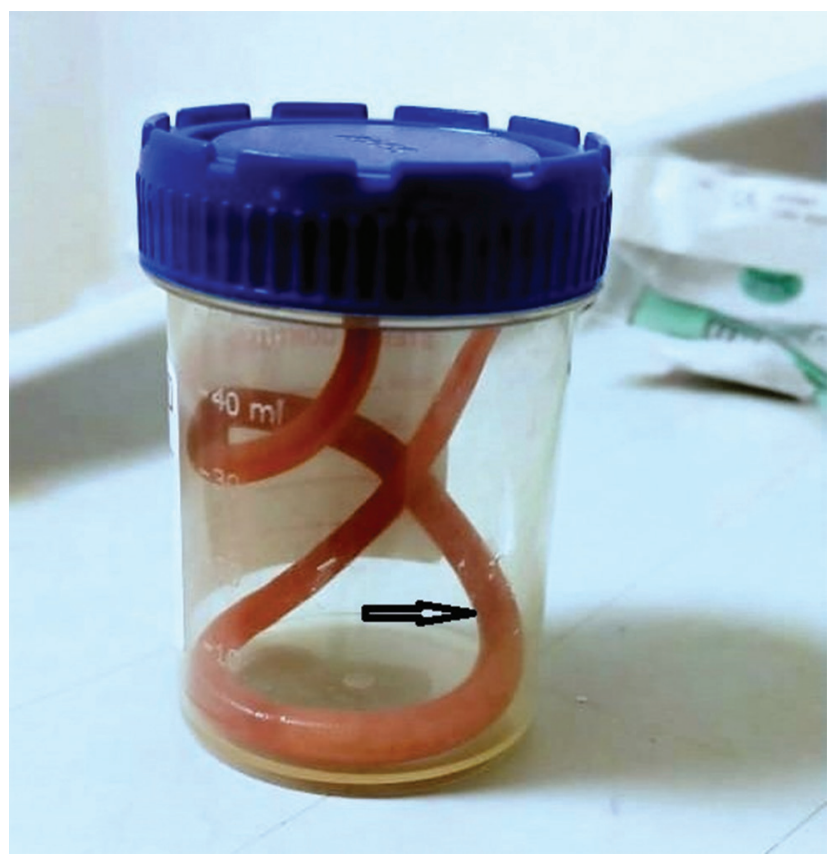

Fig. 2 Long Ascaris Lumbricoides worm (arrow).

reflex, cough reflex produced by deep suctioning of oropharynx, reduced gastric $\mathrm{pH}$ and pepsin release by the use of proton-pump inhibitors. Migration of adult worms up to the esophagus and subsequent entry into airway can also result from subtherapeutic anthelmintic therapy, irritation caused by anthelmintic drugs, and effect of anesthetic drugs. ${ }^{4}$ Ascaris seems to be particularly sensitive to anesthetic agents, as they stimulate the worm to be hypermobile. ${ }^{5}$ Fatal and near-fatal airway obstruction, obstruction of vocal cords, laryngospasm, and lung collapse have all been reported in extubated patients after aspiration of ascaris worm during coughing or vomiting. ${ }^{6.7}$ Patients with altered sensorium, or those under effect of anesthesia/sedation, are more likely to suffer from fatal respiratory obstruction. Life-threatening airway obstruction has been reported even in intubated patients by migration of the worm into the trachea with noncuffed or loosely-fitted endotracheal tube. ${ }^{8}$ Serious, unexplained hyperthermia resulting from ascaris infection has been reported in a postoperative cardiac surgical patient. ${ }^{9}$

The case emphasizes the importance of adequate deworming before elective surgery in a patient of eosinophilia, particularly for those living in endemic areas. We also suggest to keep the head end of the patient elevated by 30 to $40^{\circ}$ while on ventilator, in order to reduce the incidence of upward migration of the worm.

\section{Conflicts of Interest}

None declared.

\section{References}

1 Mahmoud AA, Intestinal nematodes. In: Mandell GI, Douglas RG, Bennet JE, eds. Principles and Practice of Infectious Diseases. Edinburg: Churchill Livingstone; 1990:2137-2138

2 Wani ML, Rather AA, Parray FQ et al. Wandering ascaris coming out through the abdominal wall. Int J Prev Med 2013;4(6): 720-722

3 Das AK. Hepatic and biliary ascariasis. J Glob Infect Dis 2014; 6(2):65-72

4 Goldsmith RS, Infectious diseases. Protozoal and helminthic infections. In: McPhee SJ, Papadakis MA, Turney LM Jr, eds. Current Medical Diagnosis Treatment. 46th ed. McGraw Hill (Medical); 2007:1517-1520

5 Ramamoorthy KG. Anaesthesia and Ascaris pneumonia (Loeffler's syndrome). Indian J Anaesth 2015;59(2):125-126

6 Singh R, Garg C, Vajifdar H. Near fatal respiratory obstruction due to Ascaris lumbricoides. Trop Doct 2005;35(3):185

7 Ugras SK, Finley DJ, Salemi A. Ascaris lumbricoides infection causing respiratory distress after coronary artery bypass grafting. Surg Infect (Larchmt) 2010;11(2):177-178

8 Bharati SJ, Chowdhury T, Goyal K, Anandani J. Airway obstruction by round worm in mechanically ventilated patient: An unusual cause. Indian J Anaesth 2011;55(6):637-638

9 Maekawa Y, Sakamoto T, Umezu K, Ohashi N, Harada Y, Matsui $\mathrm{H}$. Hyperthemia after cardiac surgery due to ascariasis in a child: report of a case. Gen Thorac Cardiovasc Surg 2012;60(7): 446-448 